\title{
Emerging treatments for overactive bladder: clinical potential of botulinum toxins
}

\author{
This article was published in the following Dove Press journal: \\ Research and Reports in Urology \\ 21 May 2014 \\ Number of times this article has been viewed
}

\section{Douglas G Tincello ${ }^{1,2}$ \\ Tina Rashid ${ }^{2}$ \\ Vladimir Revicky ${ }^{2}$}

'Reproductive Sciences Section, Cancer Studies and Molecular Medicine, University of Leicester, Leicester, UK; ' $U$ rogynecology Unit, Women's and Children's Clinical Business Unit, University Hospitals of Leicester National Health Service Trust, Leicester, UK
Correspondence: Douglas G Tincello Reproductive Sciences Section, Cancer Studies and Molecular Medicine, Robert Kilpatrick Clinical Sciences Building, University of Leicester, Leicester Royal Infirmary, PO Box 65 , Leicester LE2 7LX, UK

Tel +44 II6 2523165

Email dgt4@le.ac.uk
Abstract: Overactive bladder (OAB) is a symptom syndrome including urgency, frequency, and nocturia - with or without incontinence. It is a common manifestation of detrusor overactivity (DO). DO is a urodynamic observation of spontaneous or provoked contractions of the detrusor muscle is seen during the filling phase of the micturition cycle. OAB is, therefore, both a motor and sensory disorder. Botulinum toxin is a purified form of the neurotoxin from Clostridium botulinum and has been used in medicine for many years. Over the last 10 years, it has been used for the treatment of DO and OAB when standard treatments, such as bladder training and oral anticholinergic medication, have failed to provide symptom relief. Botulinum toxin acts by irreversibly preventing neurotransmitter release from the neurons in the motor end plate and also at sensory synapses, although the clinical effect is not permanent due to the growth of new connections within treated tissues. It is known that botulinum toxin modulates vanillioid, purinergic, capsaicin, and muscarinic receptor expression within the lamina propria, returning them to levels seen in normal bladders. Clinically, the effect of botulinum toxin on symptoms of $\mathrm{OAB}$ and DO is profound, with large effects upon the symptom of urgency, and also large effects on frequency, nocturia, leakage episodes, and continence rates. These effects have been seen consistently within eight randomized trials and numerous case series. Botulinum toxin appears safe, with the only common side effect being that of voiding difficulty, occurring in up to $10 \%$ of treated patients. Dosing regimens are variable, depending on which preparation is used, but it is clear that dose recommendations have fallen over the last 5 years. There is limited evidence about the efficacy of repeat treatments. Botulinum toxin is an effective and safe second-line treatment for patients with OAB and DO.

Keywords: overactive bladder, detrusor overactivity, botulinum toxin, efficacy, side-effects, treatment

\section{Introduction to overactive bladder Definitions}

Overactive bladder $(\mathrm{OAB})$ is a descriptive term, defined by the International Continence Society as the urinary symptoms of urgency, with or without urge urinary incontinence, usually associated with frequency and nocturia. ${ }^{1}$ Detrusor overactivity (DO), although associated with $\mathrm{OAB}$, is a urodynamic observation characterized by involuntary contractions during the filling phase, which may be spontaneous or provoked. ${ }^{1}$ DO is further divided into idiopathic DO (IDO), ie, DO with no clear cause, and neurogenic DO (NDO), which is DO in a patient with an underlying neurological condition (commonly multiple sclerosis, or after spinal injury). It should be emphasized that $\mathrm{OAB}$ is a symptom syndrome, not a diagnosis, although many patients will show 
underlying DO if investigated. However, clinicians should remember the importance of screening for bacteriuria, frank infection, renal tract calculi, or tumors in patients with other risk factors or clinical signs.

Botulinum toxin is administered via a cystoscope and injected into the detrusor from within the bladder lumen, usually at 20-30 sites across the dome of the bladder, usually avoiding injections to the trigone. It can be administered under local or general anesthesia via rigid or flexible cystoscopy.

\section{Prevalence}

OAB is highly prevalent; $0.3 \%-75 \%$ of adults may be affected with variations in prevalence determined by the definition of $\mathrm{OAB}$, the presence or absence of urge urinary incontinence, sex, and age. ${ }^{2}$ OAB costs are related to pad use, pharmacotherapy, catheters, physician visits, outpatient and inpatient attendances as well as intangible costs, such as time and loss of productivity. ${ }^{3}$ The economic burden is significant and is comparable to the cost of breast cancer, osteoporosis, and diabetes ${ }^{4}$ with one study in Germany demonstrating the cost of OAB to be 3.57 billion Euros per year, close to the 5.1 billion Euros per year cost of diabetes and 5.6 billion Euros per year cost of dementia. ${ }^{5}$

\section{Overview of OAB management, including available therapy}

Conservative treatment options for OAB and/or DO include lifestyle modification and pelvic floor exercises. Additional treatment options include oral and transdermal medication (anticholinergics and the newer beta-three agonists) and percutaneous posterior tibial nerve stimulation.

A Cochrane Database Systematic Review of published studies has demonstrated the effectiveness of bladder training in reducing urgency or urge urinary incontinence symptoms (relative risk 17; 95\% confidence interval 1.13-256). ${ }^{6}$ If conservative treatment is ineffective, medical and surgical treatments are considered. Anticholinergic drugs are the first-line medications to treat symptoms of OAB. They block muscarinic receptors in the bladder, reducing detrusor contractions and modifying bladder sensation by interfering with afferent pathways, reducing urinary urgency and the related symptoms of urgency incontinence, frequency, and nocturia. Available preparations include oxybutynin, tolterodine, trospium, propiverine, and solifenacin. ${ }^{7}$

Mirabegron is a $\beta$-three receptor agonist and is used for treating the symptoms of OAB when anticholinergic drugs are contraindicated or clinically ineffective or have unacceptable side effects. Recent trials have been reviewed, and it appears that mirabegron is a potentially useful secondline agent. ${ }^{8}$ Recommendation on the use of these drugs has been published by the UK National Institute of Clinical Excellence (NICE). ${ }^{9}$

Percutaneous posterior tibial nerve stimulation involves percutaneous stimulation of the posterior tibial nerve in the ankle using a fine-gauge needle. The exact mechanism is unclear, but it is thought to be mediated by retrograde stimulation of the sacral nerve plexus. Currently, there is not enough evidence to recommend its use over alternative treatments, and it is not recommended for use in the UK by NICE. ${ }^{9}$

Surgical management of OAB/DO includes intravesical botulinum toxin, sacral neuromodulation, with augmentation cystoplasty and urinary diversion being reserved for end-stage disease. Sacral neuromodulation consists of the implantation of a permanent sacral nerve root stimulator, which is designed to provide chronic stimulation to the third sacral nerve root. Its use is recommended for patients with refractory OAB who have failed conservative measures (including drugs) and who cannot perform self-catheterization or who have failed botulinum toxin treatment. ${ }^{9}$ Augmentation cystoplasty increases the functional bladder capacity by incorporating a "clam patch" of bowel (usually ileum, but ileocecum may be used) into a bivalved bladder. Although $50 \%$ of patients may be cured, the morbidity with this surgery is high and should be reserved for patients who have failed other less-invasive measures. Urinary diversion is an end-stage operation offered to those in whom all other alternatives have either failed or are inappropriate. Further description of these operations and their outcomes is beyond the scope of this article.

\section{Botulinum toxin, mode of action, preparations available, administration}

Botulinum toxin serotype A (BoNT-A) is a purified neurotoxin from Clostridium botulinum. Its use was first described by Dysktra et al ${ }^{10}$ in 1988 , who identified benefit in spinalinjured patients with detrusor-sphincter dyssynergia. Since then, BoNT-A has been used in the urological setting for DO, bladder outlet obstruction (in men), and painful bladder syndrome/interstitial cystitis. Other nonurological uses include blepharospasm, cervical dystonia, chronic migraine, strabismus, hyperhidrosis, and upper limb spasticity.

\section{Mode of action}

BoNT-A blocks the presynaptic release of acetylcholine at the neuromuscular junction by permanently inactivating the 
synaptosomal-associated protein 25 (SNAP-25), a SNARE protein component, by enzymatic cleavage. ${ }^{11}$ The resulting flaccid paralysis of the injected muscle is permanent, and regrowth of the new motor end plate units is required to reestablish neuromuscular connection. In clinical terms, this can take anywhere between 3-24 months, at which point retreatment is required.

Apostolidis et $\mathrm{a}^{12}$ have proposed that BoNT-A inhibits the release of acetylcholine, adenosine triphosphate, substance $\mathrm{P}$, and reduces the expression of capsaicin and purinergic receptors on motor nerves. This results in desensitization by decreasing the central uptake of substance $\mathrm{P}$ and other neurotrophic factors, with the ultimate inhibition of the afferent and efferent pathways responsible for DO. In addition, Datta et $\mathrm{al}^{13}$ have demonstrated an increase in immunoreactivity of muscarinic receptors in the suburothelium of patients treated successfully with BoNT-A with the number of receptors being inversely proportional to patient-reported frequency and urgency.

BoNT-A also specifically modulates the sensory functions of the bladder. Biopsies from BoNT-treated bladders suggest that the neurotoxin results in a reduction in the number of expressed sensory vanilloid (transient receptor potential cation channel subfamily V member 1 [TRPV1]), purinergic (P2X3), capsaicin, and muscarinic (M1, M2, and partly M3) receptors in the suburothelium of patients with $\mathrm{DO}$, in whom these receptors are upregulated. ${ }^{14}$

This combined motor and sensory effect translates into measurable clinical effects: reduced detrusor pressure; increased bladder capacity; reduced incontinence episodes; and reductions in the sensation of urgency, with a degree of impaired bladder emptying (greater in patients with $\mathrm{NDO}^{15}$ compared with $\left.\mathrm{IDO}^{16}\right)$.

\section{BoNT-A preparations}

Seven serotypes of BoNT exist - type A-G - with the most common being type A for lower urinary tract symptoms. Currently, the pharmaceutical industry markets five different preparations of BoNT-A, but only two of these have been studied in any detail for the treatment of OAB/DO. These are: Botox ${ }^{\circledR}$ (Allergan Pharmaceuticals, Irvine, CA, USA); and Dysport ${ }^{\circledR}$ (Ipsen Biopharm Ltd, Slough, UK). Most of the published literature has used Botox ${ }^{\circledR}$. Botox ${ }^{\circledR}$ is available in ampules of 100 units (U) or $200 \mathrm{U}$ each; Dysport ${ }^{\circledR}$ is available in ampules of $500 \mathrm{U}$ each. The units are not interchangeable; $1 \mathrm{U}$ of Botox ${ }^{\circledR}$ is equivalent to 3-5 $\mathrm{U}$ Dysport $^{\circledR} .{ }^{17,18}$ Botox $^{\circledR}$ is now referred to as onabotulinum toxin A (onaBoNT-A), and Dysport $^{\circledR}$ as abobotulinum toxin A (aboBoNT-A). ${ }^{17}$

\section{Administration}

BoNT-A is stored at $2^{\circ} \mathrm{C}-8^{\circ} \mathrm{C}$ as a dry powder that must be reconstituted in $0.9 \%$ normal saline without agitation, which may denature the neurotoxin. It may be administered under local or general anesthesia using the 5 French $35 \mathrm{~cm}$ injection needle, with a tip length of $4 \mathrm{~mm}$. Prior to BoNTA administration, patients must be free of urinary tract infection. Aminoglycoside antibiotics are relatively contraindicated, because they can potentiate the neuromuscular blockade effect of BoNT-A. Anticoagulants, such as aspirin, clopidogrel, and warfarin, do not need to be stopped prior to treatment.

The optimum injection protocol (ie, number and placement of injections) has yet to be standardized. Most authors inject $10 \mathrm{U}$ of onaBoNT-A per injection site (diluted in $0.5-1.0 \mathrm{~mL}$ ) and will inject 20 sites, sparing the trigone, for idiopathic DO or OAB. Most clinicians have avoided the injection of the trigone because of the concerns about paralysis of the muscle near the ureteric orifices leading to vesicoureteric reflux. However, Manecksha et $\mathrm{al}^{19}$ demonstrated that trigone-including injections were superior to trigone-sparing injections for the treatment of refractory IDO with no increase of vesicoureteric reflux. This was a prospective randomized controlled trial (RCT), but it only included 22 patients. There is some evidence suggesting that these injections may offer some improvement but perhaps not affect the duration of action. ${ }^{20}$

\section{Efficacy data from studies on patients with neuropathic DO}

onaBoNT-A was first studied as a treatment for neurogenic detrusor overactivity (NDO) after spinal injury or multiple sclerosis. The main problem here is detrusor-sphincter dyssynergia, incontinence, and enuresis. The majority of NDO patients are catheterized, and very often they are troubled by catheter expulsion or catheter bypassing.

Initially, onaBoNT-A was administered at $300 \mathrm{U}$ for NDO, but there has been a move toward using $200 \mathrm{U}$ in more recent trials. A placebo-controlled RCT, comparing $200 \mathrm{U}$ or $300 \mathrm{U}$ of onaBoNT-A, reported $50 \%$ improvement in incontinence episode frequency and urodynamic measurements in either dosage group, which confirmed that either dose was effective and safe. ${ }^{21}$

Cruz et a ${ }^{15}$ randomized NDO patients (multiple sclerosis or spinal injury) to receive either $200 \mathrm{U}$ or $300 \mathrm{U}$ of onaBoNT-A, or placebo. Both doses reduced weekly incontinence episode frequency within 6 weeks (mean reduction of -21.8 and -19.4 , respectively), and urodynamic 
variables improved in parallel, suggesting the doses were equally effective.

Ginsberg et a ${ }^{22}$ conducted a very similar RCT that recruited 416 patients and demonstrated analogous improvements with a clear-dose response in the risk of postinjection voiding dysfunction and so concluded that $300 \mathrm{U}$ had no clinical benefits over a dose of $200 \mathrm{U}$. Now the usual starting dose for treatment of patients with NDO is $200 \mathrm{U}$.

\section{Efficacy data from studies on patients with IDO or OAB}

There was a need for caution when considering the potential benefits of BoNT-A for patients with IDO compared to the outcomes in NDO. Patients with IDO have different troublesome symptoms, which are mainly of urgency, frequency, and nocturia. In contrast to NDO, where many patients use longterm catheterization, the onset of voiding difficulties after treatment would be a more troublesome adverse outcome. Thus, most authors began with a lower dose for treatment (eg, $200 \mathrm{U}$ of onaBoNT-A or $300 \mathrm{U}$ of aboBoNT-A). Early work demonstrated that treatment of IDO patients resulted in symptom improvement and changes in urodynamic measurements, which were very similar to those seen in NDO. ${ }^{23}$

As mentioned earlier, OAB is closely related to DO, but not all patients will show detrusor contractions during the urodynamic investigation. This distinction between $\mathrm{OAB}$ and DO discussed above becomes relevant when analyzing the available literature on the efficacy of botulinum toxins, because some of the first RCTs only included patients with proven DO; ${ }^{24-26}$ whereas, some cohort studies and later $\mathrm{RCTs}^{16,27-29}$ recruited patients with OAB (without urodynamic confirmation) as a mixed sample, or - in some studies - as only patients with $\mathrm{OAB}$. The latter studies have shown that symptomatic improvement from BoNT-A in patients with $\mathrm{OAB}$ is equivalent to that with demonstrable DO. BoNT-A is increasingly offered to patients with $\mathrm{OAB}$ symptoms alone on the basis of these studies, but it should be remembered that not all these patients will have DO.

Many nonrandomized studies have reported the effects of BoNT-A in patients with IDO and demonstrated improvements in OAB symptoms, such as urgency and frequency of urination, incontinence, use of continence pads, and diseasespecific quality-of-life (QOL) outcome measures. However, there are now eight RCT studies assessing the efficacy of BoNT-A as a treatment for IDO. The first RCT compared the effect of $200 \mathrm{U}$ of onaBoNT-A with placebo in a mixed-sex sample of 34 participants. ${ }^{24}$ Significant increases in bladder capacity occurred with symptomatic improvement, which was maintained for 6 months by 16 patients treated with active drug. The second RCT investigated the effects of 200 $\mathrm{U}$ or $300 \mathrm{U}$ of onaBoNT-A in comparison to the placebo. ${ }^{25}$ At 6 weeks, all 15 women treated with active drug showed: a $50 \%$ reduction in the frequency of incontinence episodes; $24 \%$ improvement in nocturia; and $12 \%$ improvement in voiding frequency compared to placebo. However, there were no longer follow-up assessments of the participants.

Brubaker et $\mathrm{al}^{16}$ conducted an RCT and showed that $72 \%$ of the treatment group (28 women) reported a minimum of $75 \%$ reduction in incontinence episodes. However, the trial was prematurely terminated, due to an excess of retention in the treatment group (albeit asymptomatic) and was, therefore, underpowered. Tincello et $\mathrm{al}^{26}$ have completed the largest single-dose RCT comparing $200 \mathrm{U}$ of onaBoNT-A to placebo in a group of 240 females over a 6-month period; they reported highly statistically significant positive changes in frequency, incontinence, and urgency episodes. In addition, $30 \%$ of the treated women became continent, and QOL measures also improved by large amounts. Also, one in six women showed some voiding dysfunction during follow-up, and approximately $30 \%$ were diagnosed with a urinary tract infection at some point during the study.

There are four RCTs of botulinum toxin in OAB alone. A dose-ranging phase III randomized study ${ }^{30}$ recruited 313 men and women with a diagnosis of OAB (funded by Allergan) and used a mixed-sex sample of 272 participants to compare doses of onaBoNT-A ( $50 \mathrm{U}, 100 \mathrm{U}, 150 \mathrm{U}, 200 \mathrm{U}$, $300 \mathrm{U}$ ). onaBoNT-A showed better outcomes at every dose compared to the placebo (urgency and weekly incontinence episodes). However, no clear dose response effect was found, although it was suggested that a dose of $150 \mathrm{U}$ was optimal. More recently, Denys et $\mathrm{al}^{27}$ reported a dose-ranging study (100 U or $150 \mathrm{U}$ versus placebo) on 107 patients (mostly women), but this was stopped before recruiting the planned sample of 152. Both doses showed benefits in OAB symptom improvement: $65 \%$ and $58 \%$ patients in the $100 \mathrm{U}$ or $150 \mathrm{U}$ dose group, respectively, reported at least 50\% improvement in symptoms; for $75 \%$ improvement, these proportions were $42 \%$. Differences in urgency and frequency episodes were significantly different from placebo in only the $150 \mathrm{U}$ group. Also, $50 \%$ of patients achieved continence at 3 months with $150 \mathrm{U}$. Urinary retention requiring catheters and infection both occurred in $10 \%$ or fewer subjects.

Nitti et $\mathrm{al}^{28}$ reported results from a large placebocontrolled RCT of $100 \mathrm{U}$ onaBoNT-A on 557 patients with $\mathrm{OAB}$. At 3 months, treated patients had greater reduction in 
daily incontinence episodes than placebo (2.65 versus 0.87 ; $P=0.001)$. Also, $22.9 \%$ of treated patients became continent (6.5\%, placebo patients). All other OAB symptom outcomes and health-related QOL scores also improved. Urinary retention was seen in $5 \%$ of subjects. Chapple et $\mathrm{al}^{29}$ randomized 548 patients who were refractory to oral medication to receive $100 \mathrm{U}$ or a placebo and reported essentially identical data. onaBoNT-A has recently been granted a license for the treatment of OAB in most European countries and in the US.

\section{Controversies Dose}

It remains unclear what the optimum dose of BoNT-A is. For IDO, recent trials show that $100 \mathrm{U}$ may be as effective as $200 \mathrm{U}$ but with a lower rate of adverse events and a lower rate of urinary retention. ${ }^{27-29}$ Whether this is offset by a more rapid return of bothersome symptoms is unclear. Some authors suggest that $150 \mathrm{U}$ may be the ideal dose to balance long efficacy with fewer adverse effects. ${ }^{30,31}$ It is not possible to comment on doses of aboBoNT-A other than $500 \mathrm{U}$ because of the lack of published evidence.

\section{Different preparations}

The majority of published data on BoNT-A for OAB/DO use the Allergan product (onaBoNT-A). It is possible that the different preparations have a different clinical profile, although there is no evidence to date to support this. There is very scant data on other available preparations of BoNT-A, such as rimabotulinum toxin B (rimaBoNT-B; Myobloc ${ }^{\circledR}$, Solstice Neurosciences, Inc., South San Francisco, CA, USA) and incobotulinum toxin A (incBoNT-A; Xeomin ${ }^{\circledR}$, Merz GmbH \& Co. KGaA, Frankfurt am Main, Germany).

\section{Repeat treatment and dosing interval}

Research into repeat BoNT-A injections suggests that there is no loss of treatment efficacy using this method, ${ }^{32,33}$ but data are limited. The optimum interval between injections is yet to be elucidated, with current practice depending on resource availability and patient symptoms. It is currently unclear whether patients will require repeat injections for life or whether a proportion of patients will achieve a cure after treatment.

\section{Cost effectiveness}

Given that it is unlikely that treatment with onaBoNT-A is curative, it is important to examine the cost-effectiveness to consider whether single or, more importantly, repeat treatments will provide acceptable cost-benefit ratios. Only one study is available to inform this question, which calculated a cost of $£ 617$ per year of symptom improvement for IDO patients. ${ }^{34}$ The calculated cost-effectiveness was $£ 30,000$ per quality adjusted life year, based upon the calculated estimates of treatment frequency, rather than a direct comparison with actual costs, since there was no comparator group. These findings need to be confirmed by prospectively collected comparative data against standard care.

\section{Conclusion and place in therapy}

BoNT-A is a highly effective treatment for symptoms of OAB and DO. The bulk of available evidence published relates to onabotulinum toxin A (BOTOX ${ }^{\circledR}$, Allergan), with some data on abobotulinum toxin A (Dysport ${ }^{\circledR}$, Ipsen). Current advice from NICE, ${ }^{9}$ the European Urological Association, ${ }^{35}$ and the 5 th International Consultation on Incontinence ${ }^{36}$ recommends that BoNT-A be reserved for patients who fail to improve with conservative treatment and medical management with two different anticholinergic drugs. Women should be counseled about the likely effect resulting in 6-9 months of symptom relief, the risk of urinary tract infection, and voiding difficulty. It may be prudent to teach self-catheterization in advance of treatment. Initial treatment of IDO can be with either $100 \mathrm{U}$ or $200 \mathrm{U}$ of onaBoNT-A. The lower dose appears to carry similar efficacy with lower rates of retention, but anecdotal evidence suggests that troublesome symptoms will return more quickly with the lower dose. The majority of patients who commence treatment with onaBoNT-A will require long-term repeat treatments. Cost-effectiveness cannot be estimated with any certainly at present, due to the lack of agreement about treatment intervals, or whether patients may achieve long-term symptom relief after a number of treatments.

This is a key issue, both for service providers and clinicians. In view of the lack of data on long-term outcomes after repeat treatment, there is currently no evidence demonstrating that repeat treatment is cost-effective, compared to sacralnerve stimulation or other second-line treatments.

\section{Disclosure}

Professor Tincello has received an honorarium for teaching related to botulinum toxin from Allergan UK. The authors report no other conflicts of interest in this work.

\section{References}

1. Abrams P, Andersson KE, Birder L, et al; Members of Committees; Fourth International Consultation on Incontinence. Fourth Internationa Consultation on Incontinence Recommendations of the International Scientific Committee: Evaluation and treatment of urinary incontinence, pelvic organ prolapse, and fecal incontinence. Neurourol Urodyn 2010;29(1):213-240. 
2. Rashid TG, Ockrim JL. Male incontinence: onabotulinum toxin A and sacral nerve stimulation. Curr Opin Urol. 2013;23(6):545-551.

3. Turner DA, Shaw C, McGrother CW, Dallosso HM, Cooper NJ, MRC Incontinence Team. The cost of clinically significant urinary storage symptoms for community dwelling adults in the UK. BJU Int. 2004;93(9):1246-1252.

4. Hu TW, Wagner TH. Economic considerations in overactive bladder. Am J Manag Care. 2000;6(Suppl 11):S591-S598.

5. Klotz T, Brüggenjürgen B, Burkart M, Resch A. The economic costs of overactive bladder in Germany. Eur Urol. 2007;51(6):1654-1662; discussion1662-1663.

6. Wallace SA, Roe B, Williams K, Palmer M. Bladder training for urinary incontinence in adults [review]. Cochrane Database Syst Rev. 2004;1:CD001308.

7. Madhuvrata P, Cody JD, Ellis G, Herbison GP, Hay-Smith EJ. Which anticholinergic drug for overactive bladder symptoms in adults [review]. Cochrane Database Syst Rev. 2012;1:CD005429.

8. Chapple CR, Cardozo L, Nitti VW, Siddiqui E, Michel MC. Mirabegron in overactive bladder: a review of efficacy, safety, and tolerability. Neurourol Urodyn. 2014;33(1):17-30.

9. Smith A, Bevan D, Douglas HR, James D. Management of urinary incontinence in women: summary of updated NICE guidance. BMJ. 2013;347:f5170.

10. Dysktra DD, Sidi AA, Scott AB, Pagel JM, Goldish GD. Effects of botulinum A toxin on detrusor-sphincter dyssynergia in spinal cord injury patients. J Urol. 1988;139(5):919-922.

11. Dolly O. Synaptic transmission: inhibition of neurotransmitter release by botulinum toxins. Headache. 2003;43 Suppl 1:S16-S24.

12. Apostolidis A, Popat R, Yiangou Y, et al. Decreased sensory receptors P2X3 and TRPV1 in suburothelial nerve fibers following intradetrusor injections of botulinum toxin for human detrusor overactivity. $J$ Urol. 2005;174(3):977-982; discussion 982-983.

13. Datta SN, Roosen A, Pullen A, et al. Immunohistochemical expression of muscarinic receptors in the urothelium and suburothelium of neurogenic and idiopathic overactive human bladders, and changes with botulinum neurotoxin administration. $J$ Urol. 2010;184(6):2578-2585.

14. Apostolidis A, Dasgupta P, Fowler CJ. Proposed mechanism for the efficacy of injected botulinum toxin in the treatment of human detrusor overactivity. Eur Urol. 2006;49(4):644-650.

15. Cruz F, Herschorn S, Aliotta P, et al. Efficacy and safety of onabotulinumtoxinA in patients with urinary incontinence due to neurogenic detrusor overactivity: a randomised, double-blind, placebo-controlled trial. Eur Urol. 2011;60(4):742-750.

16. Brubaker L, Richter HE, Visco A, et al. Refractory idiopathic urge urinary incontinence and botulinum A injection. J Urol. 2008;180(1): $217-222$.

17. Mangera A, Andersson KE, Apostolidis A, et al. Contemporary management of lower urinary tract disease with botulinum toxin $\mathrm{A}$ : a systematic review of botox (onabotulinumtoxinA) and dysport (abobotulinumtoxinA). Eur Urol. 2011;60(4):784-795.

18. Grosse J, Kramer G, Jakse G. Comparing two types of botulinum-A toxin detrusor injections in patients with severe neurogenic detrusor overactivity: a case-control study. BJU Int. 2009;104(5):651-656.

19. Manecksha RP, Cullen IM, Ahmad S, et al. Prospective randomised controlled trial comparing trigone-sparing versus trigone-including intradetrusor injection of abobotulinumtoxinA for refractory idiopathic detrusor overactivity. Eur Urol. 2012;61(5):928-935.

20. Chapple CR. Which preparation of botulinum toxin a should be used, where should it be injected, and how should its efficacy be assessed? Eur Urol. 2012;61(5):936-937.

21. Schurch B, de Sèze M, Denys P, et al; Botox Detrusor Hyperreflexia Study Team. Botulinum toxin type a is a safe and effective treatment for neurogenic urinary incontinence: results of a single treatment, randomized, placebo controlled 6-month study. J Urol. 2005;174(1): 196-200.
22. Ginsberg D, Gousse A, Keppenne V, et al. Phase 3 efficacy and tolerability study of onabotulinumtoxinA for urinary incontinence from neurogenic detrusor overactivity. $J$ Urol. 2012;187(6):2131-2139.

23. Popat R, Aspostolidis A, Kalsi V, et al. A comparison between the response of patients with idiopathic detrusor overactivity and neurogenic detrusor overactivity to the first intradetrusor injection of botulinum-A toxin. J Urol. 2005;174(3):984-989.

24. Sahai A, Khan MS, Dasgupta P. Efficacy of botulinum toxin-A for treating idiopathic detrusor overactivity: results from a single center, randomized, double-blind, placebo controlled trial. J Urol. 2007;177(6): 2231-2236.

25. Flynn MK, Amundsen CL, Perevich M, Liu F, Webster GD. Outcome of a randomized, double-blind, placebo controlled trial of botulinum A toxin for refractory overactive bladder. J Urol. 2009;181(6): 2608-2615.

26. Tincello DG, Kenyon S, Abrams KR, et al. Botulinum toxin a versus placebo for refractory detrusor overactivity in women: a randomised blinded placebo-controlled trial of 240 women (the RELAX study). Eur Urol. 2012;62(3):507-514.

27. Denys P, Le Normand L, Ghout I, et al; VESITOX study group in France. Efficacy and safety of low doses of onabotulinumtoxinA for the treatment of refractory idiopathic overactive bladder: a multicentre, double-blind, randomised, placebo-controlled dose-ranging study. Eur Urol. 2012;61(3):520-529.

28. Nitti VW, Dmochowski R, Herschorn S, et al; EMBARK Study Group. OnabotulinumtoxinA for the treatment of patients with overactive bladder and urinary incontinence: results of a phase 3, randomized, placebo controlled trial. J Urol. 2013;189(6):2186-2193.

29. Chapple C, Sievert KD, MacDiarmid S, et al. OnabotulinumtoxinA $100 \mathrm{U}$ significantly improves all idiopathic overactive bladder symptoms and quality of life in patients with overactive bladder and urinary incontinence: a randomised, double-blind, placebo-controlled trial. Eur Urol. 2013;64(2):249-256.

30. Dmochowski R, Chapple C, Nitti V, et al. Efficacy and safety of onabotulinumtoxinA for idiopathic overactive bladder: a double-blind, placebo controlled, randomized, dose ranging trial. J Urol. 2010;184(6): 2416-2422.

31. Cohen BL, Barboglio P, Rodriguez D, Gousse AE. Preliminary results of a dose-finding study for botulinum toxin-A in patients with idiopathic overactive bladder: 100 versus 150 units. Neurourol Urodyn. 2009;28(3):205-208.

32. Kennelly M, Dmochowski R, Ethans K, et al. Long-term efficacy and safety of onabotulinumtoxinA in patients with urinary incontinence due to neurogenic detrusor overactivity: an interim analysis. Urology. 2013;81(3):491-497.

33. Gousse AE, Kanagarajah P, Ayyathurai R, Handa P, Dabas N, Gomez CS. Repeat intradetrusor injections of onabotulinum toxin a for a refractory idiopathic overactive bladder patients: a singlecenter experience. Female Pelvic Med Reconstr Surg. 2011;17(5): 253-257.

34. Kalsi V, Popat RB, Apostolidis A, et al. Cost-consequence analysis evaluating the use of botulinum neurotoxin-A in patients with detrusor overactivity based on clinical outcomes observed at a single UK centre. Eur Urol. 2006;49:519-527.

35. Lucas MG, Bosch RJL, Burkhard FC, et al; European Association of Urology. EAU guidelines on surgical treatment of urinary incontinence. Eur Urol. 2012;62(6):1118-1129.

36. Abrams P, Cardozo L, Khoury S, Wein A, editors. Incontinence: Fifth Edition 2013, Paris, France, 24-25 February 2012. Arnhem, The Netherlands: European Association of Urology; 2013. 
Research and Reports in Urology

\section{Publish your work in this journal}

Research and Reports in Urology is an international, peer-reviewed, open access journal publishing original research, reports, editorials, reviews and commentaries on all aspects of adult and pediatric urology in the clinic and laboratory including the following topics: Pathology, pathophysiology of urological disease; Investigation and treatment of

urological disease; Pharmacology of drugs used for the treatment of urological disease. The manuscript management system is completely online and includes a very quick and fair peer-review system, which is all easy to use. Visit http://www.dovepress.com/testimonials.php to read real quotes from published authors.

Submit your manuscript here: http://www.dovepress.com/research-and-reports-in-urology-journal 